\title{
THE BOSTON
}

\section{MEDICAL ANI) SURGICAL JOURNAL.}

VOL. XCIII. - THURSDAY, NOVEMBER 4, 1875. - NO. 19.

REPOR'S OF SIXTEEN CASLS OF CA'TARACT OPERA'TIONS.'

ISY B. JOY JEFFRIES, M. D., OF BOSTON,

Ophthalmic Surgeon to the Massarhusserts Eygr and Ear Infirmary, the C'arney Mespital, and the New Singland IIospital.for Women and Children.

Last season I published in the Journar ${ }^{2}$ the reeords of one hundred and five cases of cataract operations, in seventy-one of which I used Graefe's operation for other than congenital, soft, or traumatic caltaracts. 'To these I have now to add the records of sixteen more case's, being those which I have done since last season. The resulting vision in all comes within the range of suceess, and they therefore bring up the percentage. The relations of the family physician, the ophthalmic operator, and the surroundings of the cataract patient, I discussed in my previous article, and will say nothing further here on these topics.

The success I have met with I must attribute to the employment of Graefe's method of operating, from which I have varied only as the individual case required. Whilst in some or many of these eightyseven cases I could have used the old flap operation with equal suceess, on the other hand, Gracfe's operation alone was in place in all. I have not yet seen reason to depart from it, as I believe it gives me the largest number of suceessful operations. I was taught the old flap operation in Europe. Gracfe's method came into use after my return, and I adopted it as soom as I became convinced of its superiority from its adaptability to all cases of cataract extraction.

In looking over my cases I can realize how valuable this method is, for I recounize many in which I should hardly have dared attempt any other. I have not thoughit it grood ophthalmic surgery to try to prove by practice or precept in what way other than Graefe's modified linear extraction a cataract could be removed, but rather by the steady use of it, as most in place in all cases, to give my patients the best chance so far as the operation was concepned. That cataracts can be removed, and sucessfully, by various cuts through the cornca, I know and admit,

1 Rend before the Sullolk 1)istrict Medient Society.

* Boston Medical and Surgical Journal, Oetober 1, 1874. 
but to mo Graefe's operation still seems the safest and, as time shows, the most usefiul.

My fricul Mr. Carter, in his recent work, has expressed these relations so practically and clearly that I can best serve my own purpose by quoting them at some length here. After explaining how Graefe was led to his operation and discussing the subsequent introduction of various forms of spoons, he says, "From this time onwards the history of cataract extraction bear's a great surgical analogy to the history of ovariotomy; for just as one by one the causes of death have been eliminated fiom the latter operation by careful study and sucessive setting aside of the conditions which tended to the production of a fatal result, so in like manner the causes of failure have been eliminated from the former. Von Graefe then strove to combine an incision so small that it should produce little risk of corneal sloughing with one so made and so situated that it should permit the exit of the lens withont injurions pressure. 'The result was that method of ' modified linear-extraction ' which was the last of his great contributions to the art he loved so well. But in order that Graefe's incision should avoid the cornea, and should at the same time preserve the direction of a plane passing from the margin of the cornea throngh the centre of the eyeball, it became necessary that its extremities should lie very near to the ciliary region; and hence arose the danger already mentioned of inflicting an injury liable to be followed by cyclitis and irido-choroiditis in the eye which was operated upon, and by sympathetic ophthahmia in its fellow. In order to avoid these risks, many operator's prefer a somewhat more extended incision in an anterior plane, not, as in the old method, in a plane parallel to the iris, but in one which, although inclined with reference to the iris, would not pass through the centre of the globe. In this preference I myself concur, and perhajs the best rules for making such an incision are those which have been laid down by M. de Wecker. I do not think, however, that an experienced operator will allow himself to be very closely bound by any rules of procedure, but he will vary every operation a little, in accordance with the size and prominence of the eye, the position of the comea, and the estimated size of the hard nucleus of the lens."

As to various innovations proposed by one or another, Mr. Carter is quite outspoken, and with what he says I must agree. "During the period," he remarks, "when real and important changes were being effected in the methods by which eataracts were removed, the surgeons engaged in the work had many followers who made changes which for the most part were only apparent. It is hardly possible for two pairs of human hands, especially if endowed with different degrees of skill, to execute all the steps of a complicated operation precisely in the same way; and so it came about that each of several operators found it more convenient to himself, more suited to the requirements of his own eyes 
and fingers, to deviate in some minute point of detail from the practice of somebody else, of whom, nevertheless, he was in the main an imitator. Of such changes there were none really worthy of record, or which possessed more than a fleeting or personal interest. 'They mostly suggested themselves as natural correctives to some kind of manual incapacity, and will suggest themselves again, as it were instinctively, to those who share the defect:s of dexterity in which they had their origin."

As to the various transverse corneal incisions for eataract-extractions, I am agrecably surprised to find Mr. Carter so. entirely agreeing with my own views and experiences. He says, "Transverse corneal incisions stand self-condemned on a priori grounds. They have the single recommendation that it is very easy to make them, and they might perhaps be attempted with advantage by a benevolent traveler who was sojourning among a savage tribe, or by an ophthalmic surgeon upon whom the infirmities of age were ereeping, or by one who was prevented by the natural quality of ambi-sinistrousness fiom employing better methods with ordinary prospects of suceess. Even in such cases Lord Melbourne's pitliy inquiry, 'Could n't you have let it alone?' would be likely to suggest itself to reasonable men. As a matter of first principles, an incision through the liont of the cornea must in a large proportion of cases be followed by adhesion of the iris to some part of the cicatrix ; and adhesion of the iris, even if vision is for a time restored, entails a perpetual liability to the occurrence of destructive morbid changes. Moreover, again in a large proportion of cases, such an incision must be followed by alteration of curvature during the healing process, that is to say, by such a distortion of the cornea as to interfere seriously with vision. We see this every now and then in clean corneal wounds made accidentally by broken enlass or by some sharp instrument, and in which the lens has escaped injury. It was seen still more firequently a few years ago, when flap-extraction was commonly performed, in the eases in which that operation had been badly done. On all the above grounds I have abstained from secking any personal experience of transverse comeal sections, feeling that they cannot be salid to fall within the boundaries of legitimate surgical experincent." 


\section{Reports of Sixteen Cases of Cataract Operations. [November 4,}

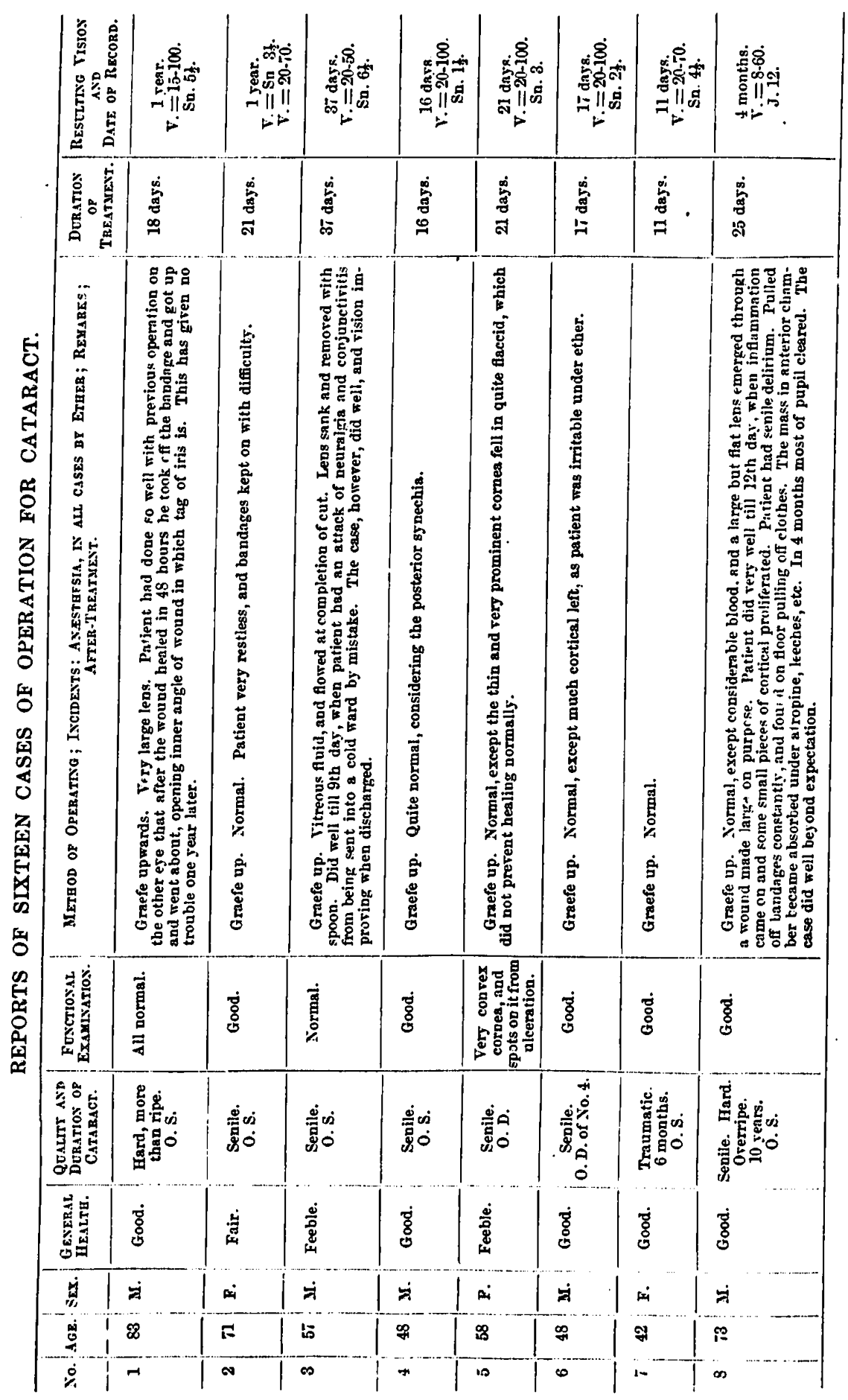


1875.] Reports of Sixteen Cases of Cataract Operations.

\begin{tabular}{|c|c|c|c|c|c|c|c|}
\hline 离 & 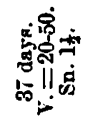 & 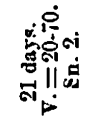 & 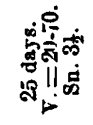 & 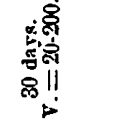 & 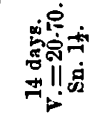 & 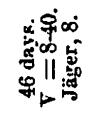 & 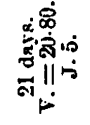 \\
\hline 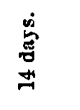 & 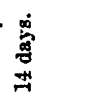 & $\frac{\dot{5}}{\overrightarrow{3}}$ & 离 & 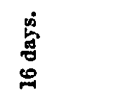 & 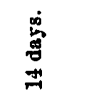 & 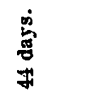 & 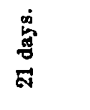 \\
\hline 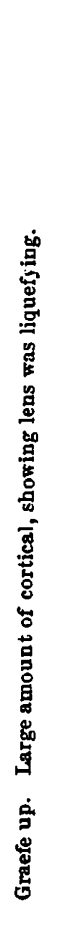 & 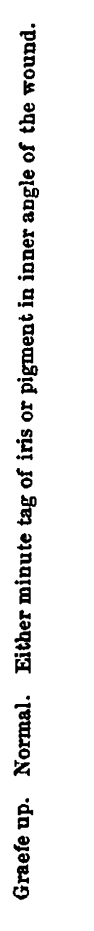 & 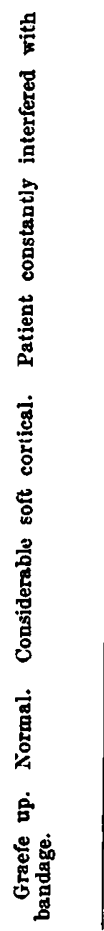 & 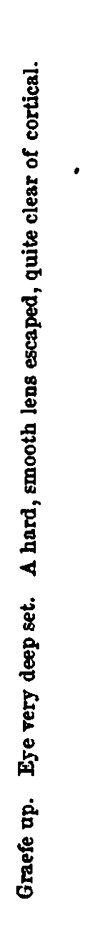 & 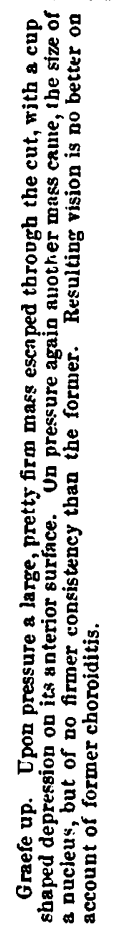 & 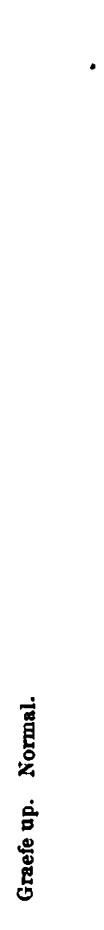 & 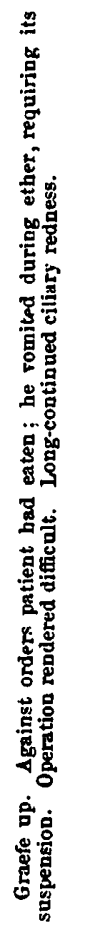 & 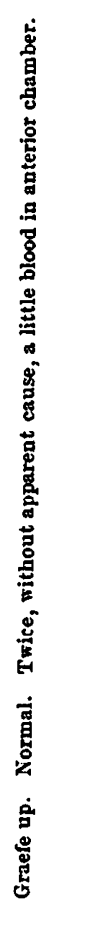 \\
\hline : & ن & 安 & 悹 & 客 & 官 & 客 & ठ் \\
\hline 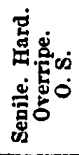 & 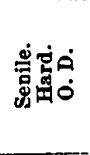 & 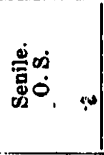 & 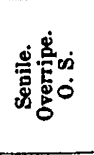 & 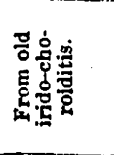 & 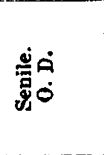 & 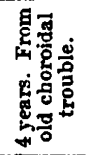 & 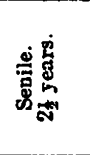 \\
\hline 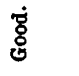 & : & 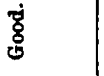 & 富 & 崫 & 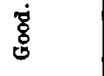 & 㟧 & 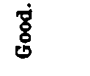 \\
\hline$\dot{H}$ & $\dot{x}$ & $\dot{x}$ & ن & si & में & में & $\dot{x}$ \\
\hline ㅇ & 8 & 8 & 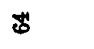 & 1988 & 18 & 8 & 8 \\
\hline$\infty$ & \& & $\Rightarrow$ & 9 & 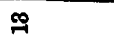 & $\exists$ & I & 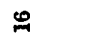 \\
\hline
\end{tabular}

